\title{
Market-driven or policy-directed certification?
}

\author{
Philippos Karipidis - Dimitrios Tselempis - Ioanna Karypidou \\ Stamatis Aggelopoulos
}

\begin{abstract}
Purpose of the paper: This study examines whether there is a balance between the impact of market factors and policy factors that accelerate certification, such that a divergence between the supply and demand of certified food is avoided.

Methodology: A value co-creation framework and a discrete choice model are developed to analyze the acceleration of certification. The model is empirically investigated with quantitative data, collected from 231 Greek certified farm businesses.

Findings: Five market and policy factors accelerate certification. Policy factors outperform market factors, but because the most crucial factor is control exertion by authorities, this is not expected to unbalance the development of the certified food subsector. The role of private standards in shifting from public to private food-sector governance is also confirmed.

Research limitations: The model estimation is based on aggregated data in the sense that five quality schemes are included; thus, some information may have been overlooked.

Implications: The theoretical framework can be used in future empirical analyses, especially when the certification decisions of small and medium-sized enterprises are examined. Public authorities should be cautious about altering the structure of incentives for farm businesses; certifiers should make certification more attractive to farm businesses; marketers should encourage farmers to accelerate certifications; and farm businesses and their organizations should focus on certification efficiency.

Originality of the paper: The paper goes beyond issues considered in previous studies by focusing on the balance between market-and policy-related factors that accelerate certification, and developing a theoretical framework.
\end{abstract}

Key words: value co-creation; accelerate certification; food market

\section{Introduction}

The implementation of quality management systems (QMS) enables suppliers of agricultural and food products (farm businesses, manufacturers, wholesalers, and retailers) to create customer value by enhancing quality; thus, market forces can generate incentives for voluntary provision of higherquality food products. Research results indicate that many food suppliers, especially farm businesses, do not intend to implement QMS (Handschuch et al., 2013; Segerson, 1999); thus, financial support or subsidies are provided. Such support is unlikely to be politically acceptable in certain 
sinergie Vol. 35, N. 102, 2017

countries in the world market, or may lead in unbalanced development in the certified subsector (Argyropoulos et al., 2013; Hattam et al., 2012; Läpple and Van Rensburg, 2011; Lohra and Salomonsson, 2000). Due to the fact that policy-directed food supply is a valid means by which food quality can be effectively regulated, and as some undesirable effects can result, such as a mismatch between the supply and demand of certified food (Uematsu and Mishra, 2012; Martinez et al., 2007), the following question arises: Can the impact of market- and policy-related factors on food supply lead to an expansion of certification efforts, thereby avoiding unbalanced development of quality certifications and, thus, divergence between supply and demand of certified foods?

Acknowledgement of the fact that quality certification schemes can be expedient choices in food supply explains why much has been written about the implementation of QMS in the last decade. However, as we will discuss in the literature review section, although previous studies examine farmers' certification decisions connected with the factors impacting these decisions, also incorporating certain market or policy factors, to our knowledge no study to date examines the balance between the impact of demand-related vs. that of policy-related factors. This is also highlighted by Tselempis et al., (2015), who suggests that there is a need to examine this balance between the two categories of factors. The main goal of the present study is to examine whether there is a balance between the impact of demand factors and policy factors on certification decisions, such that when this balance is achieved, a divergence between the supply and demand of certified foods is avoided. Since the analysis is based on the acceleration of certification decisions, we build a value co-creation framework that connects the certification decision with the two categories of factors that can impact it, thereby also introducing the time period for which the farm business has been certified into its profit function.

The empirical investigation of a discrete choice model we have built is based on data collected from certified farm businesses located on Central Macedonia (northern Greece). The findings of the study could help public authorities to build a suitable policy mix that will enable market forces to generate incentives for voluntary provision of higher-quality, certified food products, thereby avoiding disturbance of the certified food market due to the introduction of state aid rules or regulations. The findings will also be useful to food producers, their organizations, and marketers in terms of efficiently integrating value creation via certification into their marketing strategies, and for certifiers to better understand the market environment in which they provide certification services. The results are most useful for European/Mediterranean countries, wherein the average farm business size is below the EU-27 average, total liabilities lead farmers to face difficulties in accessing credit markets, and solvency indicating the farm's ability to meet its financial obligations in the long term is also very low (European Commission's Farm Economics Overview, 2012). These farm businesses can be less likely to implement quality standards and require a great deal of encouragement to become certified (Handschuch et al., 2013; Hattam et al., 2012). 
The remainder of the paper is structured as follows. Section 2 presents the literature review, followed by the theoretical framework in Section 3. Section 4 presents the hypotheses formation, followed by the depiction of the model and data collection in Section 5. Section 6 presents the model estimation, results, and discussion, while the conclusions, implications, and propositions for future research are offered in Section 7.

\section{Literature review}

Karipidis and Tselempis (2014) report several quality certification schemes that are suitable for certifications at farm business level, such as Organic Certification, GlobalGAP, Quality and Safety, Tesco Nature's Choice, and national standards (AGRO 2.1/2.2 in Greece). Organic certification differs substantially from other certification schemes in terms of its requirements, organizational structure, implementation and auditing, which are connected with differences in certification costs, customer requirements and preferences, and farm business revenues. Thus, previous studies can be grouped according to two categories of certification schemes: "organic schemes" and "other schemes".

\subsection{Organic certification schemes}

Soltani et al., (2014) investigate the main factors influencing adoption of organic schemes and report that while there are strong motives for adoption, farmers face challenges in certifying, marketing, and accessing reliable technical information and credit. Khaledi et al., (2010) use a Tobit model to identify the factors that encourage adoption of organic certification and to assess why farmers differ in the share of cultivated crop area they allocate to organic practices. Khaledi et al.'s (2010) findings suggest that small farmers are more inclined to be certified and that younger farmers allocate significantly less of their cultivated area to organic practices. Uematsu and Mishra (2012) estimate the average treatment effect of organic certification on various components of farm household income, and Handschuch et al., (2013) use an econometric model based on net benefits representing the farmer's decision to obtain certification. In contrast to Khaledi et al.'s (2010) findings, Handschuch et al., (2013) indicate that small-scale farmers are less likely to implement food safety and quality standards. Furthermore, Veldstra et al., (2014) consider the utility maximization behavior of farmers and analyze the percentage of production dedicated to organic practices and the percentage of production that is certified organic, while Läpple (2010) investigates the determinants that affect adoption and abandonment of certified organic farming over time. They highlight that when no attempt is made to account for time effects, important information about certification decisions may not be taken into consideration.

Some authors incorporate policy factors into their studies. For instance, Kuminoff and Wossink (2010) used the net present value approach to assess the compensation required to induce conventional farmers to be certified, incorporating the impact of policy changes on future return 
sinergie Vol. 35, N. 102, 2017

expectations. They suggest that sunk costs associated with conversion to organic, coupled with uncertainty about future returns, explain why there is so little organic farmland in the USA. Läpple and Van Rensburg (2011) find that later adopters, who adopted organic production after common agricultural policy subsidies were introduced, were strongly motivated to do so based on profits, while early adopters were less motivated by profit. Kallas et al., (2010) conducted duration analysis to determine why certified farmers adopt organic farming practices. They include farmers' objectives, risk preferences, and agricultural policies as covariates in their model and find that farmers' objectives influence the decision to convert to organic. Furthermore, Hattam et al., (2012) analyze organic certification decisions using a set of time-to-organic durations collected from small-scale farms. They highlight that some producers require a great deal of encouragement to become certified organic while others do not.

\subsection{Several certification schemes}

Bravo-Monroy et al., (2016) combine ethnographic techniques and quantitative methods to examine the drivers for adopting organic and conventional quality schemes. They show that not only financial factors but also some social factors drive farmer certification decisions. Aidoo and Fromm (2015) use a binary logistic regression model and suggest that the willingness to adopt cocoa certification is influenced by access to credit, awareness of certifications, the education level of farmers and farmer-based organization membership. Furthermore, Tey et al., (2015), explain the adoption of certification schemes through analysis of the role of personal values in guiding this decision, while Tselempis et al., (2015) adopt a management decision model to examine whether the implementation of a QMS and the choice of quality certification scheme are decided as responses to market conditions. They conclude that the adoption of a private quality management scheme and the acceleration of certification are market-driven choices.

Some studies adopt utility theory and agricultural household modeling to explore certification decisions. Muriithi et al., (2011) find that the high initial cost of compliance with a certification scheme is a major constraint, and that the key factors that enhance compliance include cultivated area, household size, and access to extension services. Kersting and Wollni (2012) analyze small farmers' adoption decisions through the lens of costs and perceived benefits. They suggest that farmers are more likely to adopt certification schemes if they are better educated and more experienced and if they have access to family labor, improved farming technology, and information and extension services. Furthermore, Asfaw et al., (2010a, 2010b) demonstrate that adopters and non-adopters are distinguishable by their asset holdings and household wealth, access to services, labor endowment, and level of education.

As seen from the above, previous studies identify a large number of factors connected with economic and social characteristics of farm businesses, by adopting agricultural modeling, utility function, average treatment effect approach, cost/benefit and duration analysis, ethnographic 
techniques, and quantitative methods. Though some studies include factors connected with the market and/or policy, to our knowledge no study to date examines the balance between the impact of demand- vs. policyrelated factors on farmers' certification decisions. The main objective of the present study is twofold. First, it aims to examine whether there is a balance between demand factors and policy factors which impact the acceleration of certification decisions, such that a mismatch between the supply and demand of certified foods is avoided. Second, it builds a theoretical framework that goes beyond those adopted previously by enabling the impact of marketrelated and policy-related factors on certification decisions to be examined.

\section{Theoretical framework}

\subsection{Value co-creation}

The farm business is the first actor in a food supply chain, and plays a crucial role in food quality formation. Following the logic that a firm's marketing strategy is designed to optimize customer value by increasing product-, service-, or experience- based quality (Ferrel et al., 1998), we view the farm business as a value-creating organization, which offers certified products that meet or exceed customers' needs or expectations. It also lowers the customers' monetary and non-monetary costs, such as via the reduction of risks for customers who buy and consume certified foods (Christopher and Gaudenzi, 2015; Kersting and Wollni, 2012).

In the value creation view, value is created in the firm and then exchanged with the customer, whereas in value co-creation, value is co-created by multiple stakeholders, such as suppliers, customer communities, and society (Anderson et al., 2004; Prahalad and Ramaswamy, 2004; Sheth and Uslay, 2007; Yi and Gong, 2013). Regarding quality certification, we assume that three stakeholders are involved in value co-creation: owners of the farm businesses offering certified products, the customer community, and public authorities who aim to facilitate the meeting of society's needs and interests.

We assume that farm business owners (farmers) offer certified products by investing in certification-related activities, and thus create value in alignment with customers' needs and public authorities' decisions that reflect society's desires for a higher quality of life and higher competitiveness of agricultural products. As Yi and Gong (2013) highlight, for successful value co-creation customers provide farm businesses with resources such as personal information, interpersonal relationships with potential customers, suggestions and recommendations to others, or tolerance of situations in which the products/services provided fail to meet their expectations. Public authorities create value by providing farm business owners with information and technical support or subsidies for quality-related programs, by conducting controls and exacting penalties, etc.

\subsection{Financial value}

As the co-creation of value enables financial value to be created (Haksever et al., 2004), we assume that a farm business owner who decides 
sinergie

italian journal of management Vol. 35, N. 102, 2017

to implement an optional QMS and become certified does so as it allows $\mathrm{him} / \mathrm{her}$ to create value for customers and society. Thus, financial value is created via the QMS and certification, as measured by accountingbased ratio measures, sales, cost, price, revenues, or profits. Based on the above definitions, Fig. 1 illustrates the theoretical framework we build; this focuses on the farm business' certification decision, which is affected by customers' related (demand) factors and public-policy factors. The farm business, in an attempt to increase the value that is created and, subsequently, to increase financial value, accelerates certification. That is, it provides customers and society with more total value at time $t$, by offering certified quality for a longer time, and thus can maximize its total profits. More specifically, it offers its food product at a quantity of $q=\bar{q}$ (unchanged at the time we study) and at a quality of $\mathrm{Q}$, which depends on the time $t$. It obtains a price, $p$, which depends on the quality, Q. The financial value created can be represented by the profit, defined as follows:

$$
\pi(t)=\mathrm{pq}-\mathrm{C}(\mathrm{q}, \mathrm{Q}) \text { so that } \mathrm{p}=P(\mathrm{Q}) \text { and } \mathrm{Q}=\mathrm{Q}(t)
$$

That is, the profit of the farm business at time $t$ depends on the quantity produced at time $t$ and the price, which depends on the quality $(\mathrm{Q})$ supplied at time $t$, and the cost $(\mathrm{C})$, which depends on the quantity $(q)$ produced at time $t$, and the quality $(\mathrm{Q})$ supplied at the same time. The firstorder derivative of equation (1) is:

$$
\frac{d \pi(t)}{d t}=\left[\frac{d P[Q(t)]}{d \mathrm{Q}} \bar{q}-\frac{d C}{d \mathrm{Q}}\right] \frac{d Q(t)}{d t}
$$

Fig. 1: Value co-creation by farm businesses, customers and Authorities (society)

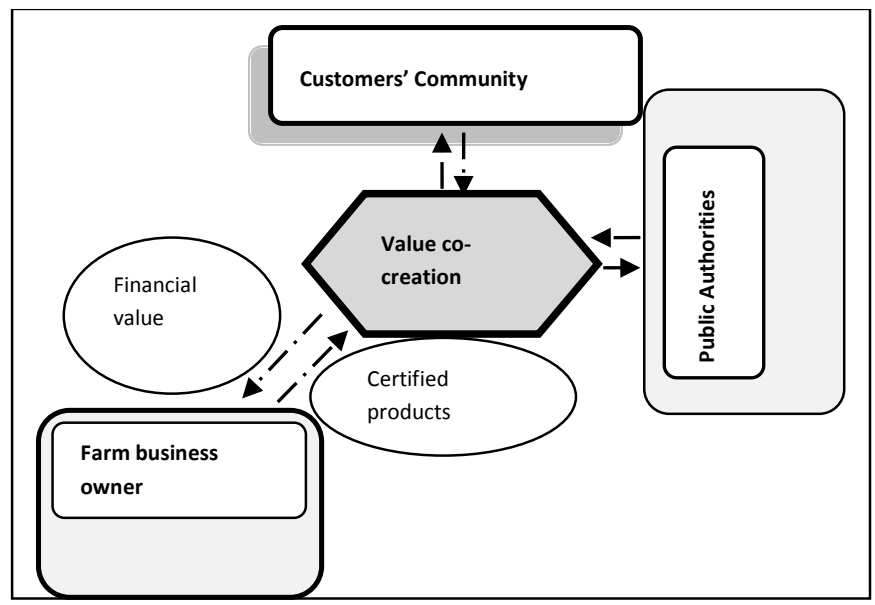

Source: Authors' elaboration

Due to the fact that the longer the period of time the farm business is certified, the greater the quantity of certified product supplied in the market $\left(\frac{d Q(t)}{d t} \geq 0\right)$, and $\frac{d P[Q(t)]^{-}}{d \mathrm{Q}} \geq 0$, while based on the $\frac{d C}{d \mathrm{Q}} \leq 0$ due to 
economies of experience in quality management and economies of size in quality certification (Ragasa et al., 2011), we expect that $\frac{d \pi(t)}{d t} \geq 0$.

Thus, it is anticipated that when the time period for which the farm business has been certified increases, its profit increases. Furthermore, when the farm business attempts to implement QMS at an early stage, we expect this to accelerate certification. Equation (2) helps us to connect the value that the farm business creates with both the financial value created and the acceleration of certification. As it would be more precise if we use the net present value of profit instead of $\pi(t)$, more details for this are given in the method section.

\section{Research hypotheses}

As stated in the introduction, some undesirable effects can result from policy-directed certification. That is, when viewed through the lens of the value co-creation framework presented above, the impact of public authorities' value creation on farm business certification decisions can outperform the impact of customers' value creation. Thus, taking into account the fact that, as reported in the introduction, no study to date has examined this issue, the first hypothesis is as follows:

H1: There is a balance between the impact of demand and public policy factors that accelerate certification, such that policy factors couldn't outperform demand factors in a way that can lead to a divergence between the supply and demand for certified food.

If the hypothesis is not accepted, the state-induced implementation of QMS will dominate the demand-related incentives and the acceleration of certification can be seen as primarily affected by public policy factors, while unbalanced diffusion of certification can be said to occur, which can lead in a mismatch between supply and demand of certified food.

Policy-directed food supply is acknowledged as a valid means through which food quality can be effectively regulated (Martinez et al., 2007), and third-party certification reflects a shift from public to private governance in the food sector (Hatanaka et al., 2005; Henson and Reardon, 2005). The development of public QMS standards or schemes available to farm businesses is a policy measure by which public authorities co-create value at the starting stage of the evolution of certifications, while private standards are developed at a later stage. Thus, it is useful to associate the type of the standard with the farm business certification decision, leading to the formulation of a second hypothesis:

H2: The extent to which the certification is accelerated depends on the type of quality certification scheme the farm business adopts.

If the hypothesis is not accepted, the validity of public policy as a means of effectively expanding certifications at the early stages will not be
Philippos Karipidis

Dimitrios Tselempis

Ioanna Karypidou

Stamatis Aggelopoulos

Market-driven or

policy-directed quality

certification? 
sinergie Vol. 35, N. 102, 2017

ascertained, and neither will the role of private standards in shifting from public to private food-sector governance. This would indicate that public authorities, certifiers, and marketers should revise their certificationrelated policies.

As stated in the literature review, organic certification differs substantially from other certification schemes. Since the organic scheme requires no synthetic agrochemicals to be used, farm businesses may view such certification as more difficult to achieve compared to other certifications. Thus, it is useful to capture the different impact of organic certification on the acceleration of certifications, compared to other certification schemes. Therefore, a third hypothesis is formulated.

H3: The choice of an organic certification scheme impacts the acceleration of certification negatively.

If the hypothesis is not accepted, it will indicate that organic certification does not differ in its impact compared to other schemes, implying that there is no need for public authorities, marketers, and certifiers to differentiate their certification-related policies.

\section{Method}

The value co-creation framework presented above enables us to connect the value a farm business co-creates with the value co-created by customers and public authorities. More specifically, the farm business creates value and, subsequently, increases financial value by investing in quality certification in order to offer certified products to customers and society. The farm business owner accelerates certification in an attempt to increase the financial value by offering certified quality for a longer time, and thereby maximizing the total profits.

\subsection{The discrete choice model}

The discrete choice model has been used to examine how decisions are influenced by the conditions under which they are realized, and to identify the factors affecting farmers' choices regarding the adoption of innovations, new methods, new technologies, and quality standards (Herzfeld et al., 2011; Wheeler, 2008) or the maintenance of certification (Karipidis and Tselempis, 2014). The focus of this study is on the acceleration of certification decisions, which reflects the time $(t)$, that is the period for which the farm business offers certified products. In the discrete choice model, the dependent variable $(y)$ is a rough categorization of a continuous but unobserved variable $\left(y^{*}\right)$. If $y^{*}$ can be directly observed, then standard regression methods can be used, such as assuming that $y^{*}$ is a linear function of some independent variables. The acceleration of certification model can take the form:

$$
y_{i}=\mathrm{a}_{i} \chi_{i}+u_{i j}
$$


$y_{i}$ is used as a proxy for $y_{i}^{*}$. According to this model, the farm business chooses alternative $i$ (time $t$ is certified). The explanatory variables reflect the factors connected with customers' value co-creation (demand side) and public authorities' value co-creation (policy measures). The $u$ values are unknown parameters to be estimated with the unknown coefficients of the variables.

The present study uses a three-point scale to measure time: in case the farm business implemented QMS at an early stage, it is considered as having remained under certification for the maximum amount of time, such that $t$ takes the maximum value of 3 . Where the farm implemented QMS at the latest stage, it is seen as being certified for the minimum time and takes the value of 1 . The relationship between the three levels of $y_{i}$ and the values of $y^{*}$ is presented in Table 1 , in correspondence with the net present value of profit instead of $\pi(t)$, as stated above, where the estimated time represents the acceleration of certification and $r$ represents the interest rate.

Tab. 1: Connecting the acceleration of certification with the net present value of the profit

\begin{tabular}{|l|l|}
\hline Estimated time & Net present value of the profit \\
\hline $\mathrm{yi}=1$ if $\mathrm{yi}^{*} \leq 1$ (late) certification) & $\pi(t)=\pi_{1}$ \\
\hline $\mathrm{yi}=2$ if $1<\mathrm{yi}^{*} \leq 2$ & $\pi(t)=\pi_{2}+(1+r) \pi_{1}$ \\
\hline $\mathrm{yi}=3$ if $2<\mathrm{yi}^{*}$ (early) certification) & $\pi(t)=\pi_{3}+(1+r) \pi_{2}+(1+\mathrm{r})^{2} \pi_{1}$ \\
\hline
\end{tabular}

Source: Authors' elaboration

\subsection{Specialization of the model}

Drawing on the findings of Tselempis et al., (2015), we introduce 11 demand-related (market) factors and five public policy factors in order to test the first hypothesis. We also add two variables in order to test the second and third hypotheses. The model (3) can take a probit or logit form. It becomes:

$$
y_{i}=\mathrm{a}_{k}^{D} X_{k}^{D}+\mathrm{a}_{j}^{P} X_{j}^{P}+\mathrm{b}_{1} Z_{1}+\mathrm{b}_{2} Z_{2}+u_{i k}
$$

where $X_{k}^{D}$ represents the demand-related factors $(k=1, \ldots, 11)$, and $X_{j}^{P}$ represents the public-policy factors $(j=1, \ldots, 5)$ that may have affected the farmer's decision. We introduce the dummy variable $Z_{1}$, which represents the type of standard the farmer adopted to examine the second research hypothesis; because 0 represents a public quality scheme and 1 represents a private scheme, it is expected that $Z_{1}$ impacts $y_{i}$ negatively. In an attempt to capture the differences in implementation decisions regarding organic certification and test the third hypothesis, the additional dummy variable $\left(Z_{2}\right)$ is introduced, taking the value of 2 in case the quality certification scheme is organic and 1 for every non-organic quality certification scheme.
Philippos Karipidis Dimitrios Tselempis

loanna Karypidou

Stamatis Aggelopo

Market-driven or
policy-directed quality certification? 


\section{sinergie}

Vol. 35, N. 102, 2017

\subsection{Data collection}

A survey, which was developed using the findings of previous studies, and a small-scale pre-test with some in-depth interviews were conducted in November and December of 2011. Modifications were made where necessary to take into account the comments and suggestions received, which primarily concerned difficulties in answering the questionnaire (including its length), and the clarity and order of the questions. The questions were answered in personal interviews conducted with the owners of certified farm businesses dispersed all over the region of Central Macedonia (northern Greece) between April and September of 2012. These farm businesses were randomly selected from a database held by the regional services of the Ministry of Agricultural Development and Food. After discarding a number of problematic questionnaires, we were able to use a total of 231 in our analysis.

\section{Empirical investigation, results, and discussion}

\subsection{Model estimation}

Estimations regarding the acceleration of certification model were conducted using the Eviews program, based on the ordered logit form; we used the Huber/White option to compute robust (quasi-maximum likelihood) estimators, in the sense that consistent estimates of parameters are produced even if the distribution is incorrectly specified. The results regarding the impact of demand-related and policy factors are presented in Table 2, including coefficient estimates, $Z$ statistics and $p$ values. This led to the null hypothesis being rejected, while it was found that all independent variables affected the variability of the dependent variable because the log likelihood value of 115.9587 is highly significant (prob. $0.000)$. The average score for the time period for which the respondents had been certified was $2.42(>2)$, meaning that most of the farm businesses in the study had implemented QMS at an early stage. Seeing that the model estimation is based on aggregated data, including the adoption of five quality certification schemes with differences among them, and because it does not include factors pertaining to the internal business environment, we do not expect the interpretation capacity of the model to be high. However, as there are no previous studies similar to the present research, the interpretative ability (pseudo R-squared 0.274416) can be considered adequate compared to the interpretative ability of analogous studies that estimate adoption models in the case of one or two specific certification schemes (Handschuch et al., 2013; Wheeler, 2008).

\subsection{Results and discussion}

As seen in Table 2, six of the 18 independent variables substantially impacted formation of the dependent variable's variability, at a significance level of 0.05 . Therefore, it can be deduced that six of the factors examined 
affected the acceleration of certification. Three of the factors pertain to the demand and affected the farm business decision positively. More specifically, the demand for certification by buyers, which will eventually lead to an increase in revenue, renders it more probable that the farm business will accelerate certification. The same applies when farm business owners are advised to become certified by buyers, and when there are local qualityrelated problems, in which the farm business tries to differentiate its products from local products and make them more attractive to potential customers.

Tab. 2: Estimation results of the model including the factors of outer environment

\begin{tabular}{|c|c|c|c|c|}
\hline Group & Factors / independent variables & Coeffic. & Z-stat. & Probab. \\
\hline \multirow{11}{*}{ 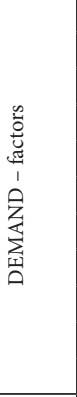 } & 1. Customers are interested in certified products & 0.385379 & 1.409865 & 0.1586 \\
\hline & 2. Buyers demand implementation of QMS & 0.513653 & 2.690321 & $0.0071^{*}$ \\
\hline & 3. Buyers demand minimum quality requirements & -0.099513 & -0.368350 & 0.7126 \\
\hline & 4. Expectations of easier selling & 0.327047 & 0.757536 & 0.4487 \\
\hline & 5. Requirement of the cooperative & -0.387998 & -0.683476 & 0.4943 \\
\hline & 6. Expectations of average price increase & 0.226610 & 1.086385 & 0.2773 \\
\hline & 7. Price uncertainty & 0.268313 & 0.778999 & 0.4360 \\
\hline & \begin{tabular}{|l|} 
8. Advice - buyers' recommendations \\
\end{tabular} & 0.371723 & 2.421393 & $0.0155^{*}$ \\
\hline & 9. Advice - suppliers' recommendations & -0.202118 & -0.817085 & 0.4139 \\
\hline & 10. Local quality defects or problems & 1.185842 & 3.372288 & $0.0007^{*}$ \\
\hline & 11. Impelling - Penalization and control exerted on behalf of the buyers & 0.343851 & 0.791612 & 0.4286 \\
\hline \multirow{8}{*}{ 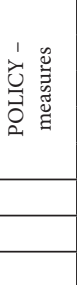 } & 1. Participation in an agricultural development programme & 0.277864 & 0.587318 & 0.5570 \\
\hline & 2. Participation in a good practice implementation programme & -0.297948 & -0.459707 & 0.6457 \\
\hline & 3. Expectation of subsidizing QMS implementation & 0.314295 & 0.817159 & 0.4138 \\
\hline & 4. Absence of provision of appropriate information / technical support & -0.736947 & -2.220721 & $0.0264^{\star}$ \\
\hline & 5. Penalisation and control exerted by the authorities & 1.465187 & 2.337578 & $0.0194^{*}$ \\
\hline & 1. Type of the standard (Public or Private) & -1.351704 & -2.118041 & $0.0342^{\star}$ \\
\hline & 2. Not organic or organic standard & 1.094579 & 1.243432 & 0.2137 \\
\hline & \multicolumn{4}{|l|}{ LR stat: 115.9587, Prob. (LR stat): 0.000000, LR index (Pseudo R-2): 0.274416} \\
\hline
\end{tabular}

Source: Authors' elaboration

Regarding the two policy factors accelerating certification, one was found to affect the decision negatively, while the other affected it positively. Specifically, failure to supply the appropriate information and technical support to farm business owners was found to negatively affect the acceleration of certification. This can be attributed to the fact that there is an information gap for the farm businesses that makes it difficult for them to assess the benefits of QMS implementation and handle the certificationrelated activities efficiently. On the other hand, the exertion of control and penalties was found to cause farm businesses to accelerate certification, as was expected.

The findings of the study concerning demand for certified products and the control exerted by authorities ascertain and complement analogous results of previous studies, such as Asfaw et al., (2010b) and Masakure et al., (2011), providing evidence of the role of lower transaction costs in the certified product market and regulatory enforcement within certification decisions in food supply chains. The findings concerning the role of information and the provision of technical assistance to farm businesses in 
sinergie Vol. 35, N. 102, 2017

their certification-related actions confirm and extend the analogous results of Muriithi et al., (2011) and Kersting and Wollni (2012). Furthermore, the findings regarding the behavior of farm businesses when local quality problems exist partially confirm and complement the results of Uematsu and Mishra (2012) concerning the impact of farm business owners' participation in a state branding program and the impact of the "regional factor" on farmers' adoption decisions.

However, the results presented above are not sufficient to answer the question regarding the balance between the impact of demand and policy factors on accelerating certification. Further study/investigation of the impact of the three demand and the two policy factors is possible by estimating the "elasticities" $\left(e_{i}=\mathrm{a}_{i} y / X\right)$. These allow us to rank the factors accelerating certification because they reflect the percentage increase or decrease (\%) in the mean probability that farmers accelerate certification if the mean value of a factor increases by $1 \%$.

The elasticities presented in Table 3 indicate that the public-policy factors outperform the demand factors, which could lead $H 1$ to be rejected. More specifically, it is observed that elasticity in the case of "control exertion by public authorities and penalization" is high $(>8.2)$, indicating that this factor accelerates certification to a degree that outperforms the acceleration caused by all the other factors together. As this factor reflects an encouragement of farm businesses to respond to mandatory quality requirements contributing to consumers' safety and enhancement of quality of life, which are in alignment with customers' interests, a divergence between supply and demand for certified food is not expected. Thus, $H 1$ is, in fact, accepted. This finding confirms and extends those of Tselempis et al., (2015) that the acceleration of certification is a market-driven choice, and the highlights of Hattam et al., (2012) that some producers require a great deal of encouragement to be certified, making government intervention with different policy measures necessary.

Tab. 3: Order of market \& policy factors

\begin{tabular}{|c|c|c|c|}
\hline \multirow{4}{*}{ 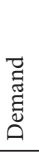 } & Factor & Elacticities & Sum \\
\hline & Buyers demand for implementation of QMS & 0,4361 & \\
\hline & Advice - buyers' recommendations & 0,3487 & \\
\hline & Local quality defects or problems & 2,5395 & 3,3243 \\
\hline \multirow{2}{*}{\begin{tabular}{l}
$\bar{y}$ \\
\hdashline \\
0
\end{tabular}} & Absence(-)/Presence(+) of appropriate information / technical support & 0,6171 & \\
\hline & Penalisation and control exerted by the authorities & 8,2456 & 8,8627 \\
\hline
\end{tabular}

Source: Authors' elaboration

Regarding the choice of a public or private type of quality certification scheme, the results indicate that public standards were mostly chosen by farm businesses that implemented QMS at an early stage, while private standards were mostly adopted by farmers that implemented QMS at a later stage. More specifically, the choice of a public certification scheme was found to be connected with the probability that the farm business accelerated certification, while the decision to adopt a private certification scheme was connected with the probability that the farm business 
implemented QMS at a late stage. Thus, H2 is supported. This result confirms and extends the report of Hatanaka et al., (2005) concerning the crucial role of third-party certifications in shifting from public to private governance in food supply, and the conclusion of Martinez et al., (2007) also go beyond those of Tselempis et al. (2015) concerning the choice of a private certification scheme by farm businesses.

Regarding $H 3$, which stated that organic certification schemes accelerate certification in a different way than do other quality certification schemes (negatively impact), the results do not provide adequate support. This implies that there is no need for public authorities, marketers, and certifiers to substantially differentiate their certification-related policies if their main goal is to accelerate quality certifications.

In conclusion, the findings indicate that the study adds substantially to the repository of literature exploring the impact of market and policy factors on the timing (acceleration) of the certification decision. Thus, we confirm Läpple's (2010) suggestion that when no attempt is made to account for time effects, important information about certification decisions may not be taken into consideration. The findings also indicate the great significance of the institutional environment and, more specifically, the market incentives and policy encouragement/discouragement needed in order for certification to be accelerated.

\section{Conclusions and implications}

\subsection{Conclusions}

The main contribution of the study is twofold. First, it examined whether there is a balance between market factors and policy factors that accelerate certification, such that a divergence between supply and demand of certified food is avoided. Second, it developed a methodology to analyze the impact of factors of institutional environment, such as the market and publicpolicy factors, on farm businesses certification. The methodology combines the value co-creation approach with a profit function and a discrete choice model, assuming that three stakeholders are involved in value co-creation: owners of the farm businesses, the customer community, and public authorities. A first conclusion of the study is that the methodology it follows is highly suitable in comparisons of demand and policy factors in relation to accelerating certification, implying that this approach should be used in a variety of cases pertaining to product markets, especially in countries and sectors characterized by small and medium-sized enterprises, such as those in the European-Mediterranean zone.

The demand factor found to have the strongest impact on the acceleration of certification is the existence of local quality problems, in response to which farm businesses try to differentiate their products from local ones. The policy factor with the strongest positive impact was identified as control exertion by public authorities and imposition of penalties. The results indicate that the public policy factors outperform demand factors, 
sinergie Vol. 35, N. 102, 2017

but because control exertion and penalization reflect the response of food suppliers to mandatory quality requirements, which are in alignment with customers' interests, a divergence between supply and demand is not expected, such as would be the case in the face of subsidy provision.

Regarding the type of quality certification scheme the farm businesses selects, the study findings reveal that: (i) policy-directed certification is a valid means by which to expand certifications effectively at an early stage of certification evolution, (ii) the efforts of market players replace policy-directed certification at a later stage, and (iii) although organic certification schemes differ substantially from other certification schemes, there is no indication that the former accelerates certification in a different way compared to the latter.

\subsection{Implications for practitioners and for future research}

As some certification-related policy measures can lead to a divergence between supply and demand in certified food markets, public authorities should be cautious not to weaken the market incentives of certification for farm businesses. More specifically, authorities should maintain or intensify quality controls or increase penalties for violations of quality rules, but should be very cautious in setting subsidies for farm businesses. They should encourage or facilitate farm businesses to accelerate QMS implementation by planning and/or supporting the proper provision of information and consultancy to farm businesses, supporting promotion campaigns to inform marketers and consumers and planning or supporting quality-related programs combined with local, regional, or national branding schemes.

Marketers/buyers of agricultural and food products should strengthen certification-related market incentives for farm businesses. More specifically, they should encourage farm businesses to accelerate certification by encouraging a preference for certified products, rewarding these businesses with higher prices, properly advising and informing food suppliers by financing information campaigns to increase consumers' awareness and demand for certified products, or providing financial support and credit to small suppliers. Special challenges arise for marketing cooperatives or groups of farmers, which can attain size economies to minimize certification costs and maximize the benefits for their members, thereby making certification more attractive to farm businesses. Farm business owners and their cooperatives can increase the efficiency of quality certification if they choose it as a response to demand, which will help farm businesses to avoid penalization. However, they need to be cautious with some forms of subsidies that may ultimately prove harmful in the long run.

An important limitation of the present paper is that the empirical investigation is based on somewhat aggregated data in the sense that five quality certification schemes were included in data collection, and thus it explores farm business' decisions to implement QMS independently of the quality certification scheme they adopted. Though our findings do not indicate a clear impact regarding the certification scheme adopted, 
future research could address this issue by considering the impact of market and policy factors for each case of the most frequently adopted individual schemes, separately, in order to gather more analytical information, which may have been overlooked in our research due to the aggregation.
Philippos Karipidis Dimitrios Tselempis Ioanna Karypidou Stamatis Aggelopoulos Market-driven or policy-directed quality certification?

\section{References}

AIDOO R., FROMM I. (2015), "Willingness to Adopt Certifications and Sustainable Production Methods among Small-Scale Cocoa Farmers in the Ashanti Region of Ghana", Journal of Sustainable Development, vol. 8, n. 1, pp. 33-43.

ANDERSON E.W., FORNELL C., MAZVANCHERYL S.K. (2004), "Customer satisfaction and shareholder value", Journal of Marketing, vol. 68 (October), pp. 172-185.

ARGYROPOULOS C., TSIAFOULI A.M., SGARDELIS P.S., PANTIS D.J. (2013), "Organic farming without organic products", Land Use Policy, vol. 32, pp. 324-328.

ASFAW S., MITHÖFER D., WAIBEL H. (2010a), "What impact are EU supermarket standards having on developing countries' export of high-value horticultural products? Evidence from Kenya", Journal of International Food \& Agribusiness Marketing, vol. 22, n. 3/4, pp. 252-276.

ASFAW S., MITHÖFER D., WAIBEL H. (2010b), "Agrifood supply chain, privatesector standards, and farmers' health: evidence from Kenya", Agricultural Economics, vol. 41, pp. 251-263.

BRAVO-MONROY L., POTTS S.G., TZANOPOULOS J. (2016), "Drivers influencing farmer decisions for adopting organic or conventional coffee management practices", Food Policy, vol. 58, pp. 49-61.

CHRISTOPHER M., GAUDENZI B. (2015), "Managing risks in sustainable supply chains", Sinergie Italian Journal of Management, vol. 33, n. 96, pp. 57-74.

FERREL O.C., MICHAEL D.H., LUCAS G.H.JR, LUCK D. (1998), Marketing Strategy, The Dryden Press, Philadelphia.

HAKSEVER C., CHAGANTI R., COOK R. G. (2004), "A model of value creation: Strategic view", Journal of Business Ethics, vol. 49, n. 3, pp. 291-305.

HANDSCHUCH C., WOLLNI M., VILLALOBOS P. (2013), "Adoption of food safety and quality standards among Chilean raspberry producers - Do smallholders benefit?", Food Policy, vol. 40, issue C, pp. 64-73.

HATANAKA M., BAIN C., BUSCH L. (2005), "Third-party certification in the global agri-food system", Food Policy, vol. 30, n. 3, pp. 354-369.

HATTAM C.E., LACOMBE D.J., HOLLOWAY G.J. (2012), "Organic certification, export market access and the impacts of policy: Bayesian estimation of avocado smallholder "times-to-organic certification" in Michoacán Mexico", Agricultural Economics, vol. 43, n. 4, pp. 441-457.

HENSON S., REARDON T. (2005), "Private agri-food standards: Implications for food policy and the agri-food system", Food Policy, vol. 30, n. 3, pp. 241-253.

HERZFELD T., DRESCHER L.S., GREBITUS C. (2011), "Cross-national adoption of private food quality standards", Food Policy, vol. 36, n. 3, pp. 401-411.

KALLAS Z., SERRA T., GIL J.M. (2010), "Farmers' objectives as determinants of organic farming adoption: the case of Catalonian vineyard production", Agricultural Economics, vol. 41, n. 5, pp. 409-23. 
KARIPIDIS P., TSELEPMIS D. (2014), "Farmers' Intention to Maintain the Quality Certification", EuroMed Journal of Business, vol. 9, n. 1, pp. 93-110.

KERSTING S., WOLLNI M. (2012), "New institutional arrangements and standard adoption: Evidence from small-scale fruit and vegetable farmers in Thailand", Food Policy, vol. 37, n. 4, pp. 452-462.

KHALEDI M., WESEEN S., SAWYER E., FERGUSON S., GRAY R. (2010), “Factors influencing partial and complete adoption of organic farming practices in Saskatchewan Canada", Canadian Journal of Agricultural Economics, vol. 58 , n. 1, pp. 37-56.

KUMINOFF N.V., WOSSINK A. (2010), "Why isn't more US farmland organic?", Journal of Agricultural Economics, vol. 61, n. 1, pp. 240-258.

LÄPPLE D. (2010). "Adoption and abandonment of organic farming: an empirical investigation of the Irish dry stock sector", Journal of Agricultural Economics, vol. 61, n. 3, pp. 697-714.

LÄPPLE D., VAN RENSBURG T. (2011), "Adoption of organic farming: are there differences between early and late adoption?", Ecological Economics, vol. 70, n. 7, pp. 1406-1414.

LOHRA L., SALOMONSSON L. (2000), "Conversion subsidies for organic production: results from Sweden and lessons for the United States", Agricultural Economics, vol. 22, n. 2, pp. 133-146.

MARTINEZ M.G., FEARNE A., CASWELL J.A., HENSON S. (2007), “Coregulation as a possible model for food safety governance: Opportunities for public-private partnerships", Food Policy, vol. 32, n. 3, pp. 299-314.

MASAKURE O., CRANFIELD J., HENSON S. (2011), "Factors affecting the incidence and intensity of standards certification evidence from exporting firms in Pakistan", Applied Economics, vol. 43, n. 8, pp. 901-915.

MURIITHI B.W., MBURU J., NGIGI M. (2011), “Constraints and determinants of compliance with EurepGap standards: A case of smallholder French bean exporters in Kirinyaga district, Kenya", Agribusiness, vol. 27, n. 2, pp. $193-$ 204.

PRAHALAD C.K., RAMASWAMY V. (2004), The Future of Competition: Cocreating Unique Value with Customers, Harvard Business School Press, Boston, 2004.

RAGASA C., THORNSBURY S., JOSHI S. (2011), "Are food certification costs missestimated? Exporter-perspective on the European standard", Journal of Agricultural Economics, vol. 62, n. 3, pp. 669-689.

SEGERSON K. (1999), "Mandatory versus voluntary approaches to food safety", Agribusiness, vol. 15, n. 1, p, pp. 53-70.

SHETH J.N., USLAY C. (2007), "Implications of the Revised Definition of Marketing: From Exchange to Value Creation", Journal of Public Policy and Marketing, vol. 26, n. 2, pp. 302-307.

SOLTANI S., AZADI H., MAHMOUDI H., WITLOX F. (2014), "Organic agriculture in Iran: Farmers' barriers to and factors influencing adoption", Renewable Agriculture and Food Systems, vol. 29, n. 2, pp. 126-134.

TEY Y.S., ARSIL P., BRINDAL M., SHAMSUDIN M.N., RADAM A., HADI A.H.I.A., RAJENDRAN N., LIM C.D., (2015), "A means-end chain approach to explaining the adoption of good agricultural practices certification scheme: the case of Malaysian vegetable farmers", Journal of Agricultural and Environmental Ethics, vol. 28, n. 5, pp. 977-990. 
TSELEMPIS D., KARIPIDIS P., PAVLOUDI A., SEMOS A. (2015), "Is the Quality Certification in Crop and Vegetable Production a Market Driven Choice in Greece?", Agricultural and Food Economics, vol. 3, n. 13, pp. 1-12.

UEMATSU H., MISHRA A. K. (2012), "Organic farmers or conventional farmers: Where's the money?", Ecological Economics, vol. 78, pp. 55-62.

VELDSTRA M.D., ALEXANDER C.A., MARSHALL M.I. (2014), “To certify or not to certify? Separating the organic production and certification decisions", Food Policy, vol. 49, n. 2, pp. 429-436.

WHEELER S.A. (2008), "What influences agricultural professionals' views towards organic agriculture?”, Ecological Economics, vol. 65, n. 1, pp. 145-154.

YI Y., GONG T. (2013), "Customer value co-creation behavior: scale development and validation", Journal of Business Research, vol. 66, n. 9, pp. 1279-1284.

\section{Academic or professional position and contacts}

\section{Philippos Karipidis}

Full Professor of Marketing of Agricultural Products

Alexander TEI of Thessaloniki - Greece

e-mail: philika@farm.teithe.gr

\section{Dimitrios Tselemp}

Post-doctoral research associate

Alexander TEI of Thessaloniki - Greece

e-mail: dimitsel@otenet.gr

\section{Ioanna Karypidou}

M.Sc in Economics - Applied Economics and Finance

University of Macedonia, Thessaloniki -Greece

e-mail: ioakaripidou@yahoo.gr

\section{Stamatis Aggelopoulos}

Full Professor of Agricultural Finance

Alexander TEI of Thessaloniki - Greece

e-mail: stamagg@farm.teithe.gr
Philippos Karipidis Dimitrios Tselempis Ioanna Karypidou

Stamatis Aggelopoulos Market-driven or policy-directed quality 